\title{
Gender perspective of HIV/AIDS Knowledge and sexual behaviour of adolescents with hearing impairment in selected special schools in Ghana
}

\author{
Cecilia Alimatu Issaka \\ Department of Educational Foundation Studies, Faculty of Education, \\ University for Development Studies, Ghana
}

\begin{abstract}
Hearing impaired youth are equally susceptible to the dangers posed by the Human Immunodeficiency Virus (HIV) and Acquired Immunodeficiency Syndrome (AIDS). The rate of contraction of the disease among adolescents with hearing impairment rests on the knowledge and sexual behaviours of the individuals. Gender and sociocultural issues are critical in facilitating adolescents' access to reproductive information and education. This study examined knowledge of HIV/AIDS and sexual behaviour of adolescents among the hearing impaired in selected special schools in Ghana. Mixed methodological design was employed in gathering both qualitative and quantitative data from 310 respondents. Findings of the study revealed that females with hearing impairment have better HIV/AIDs knowledge than their male colleagues. Female students considered more vulnerable frequently receive sex education from their parents, school authorities and from their peers.
\end{abstract}

Key words: HIV, AIDS, knowledge, behaviour, sexual, hearing impaired, Ghana

\section{INTRODUCTION}

The Human Immunodeficiency Virus (HIV) and the Acquired Immunodeficiency Syndrome (AIDS) epidemic remains and will continue to be the most serious threat to health globally. The epidemic ravages lives in most developing countries, Africa especially, and this has become a bedevilling concern for the $21^{\text {st }}$ century generation. Remarkably, people in developing countries account for $95 \%$ of all cases of the epidemic annually [1]; the developed countries seem to have understood the preventive measures rather than the cure. Adeniyi [1] notes that efforts have been systematically invested on the control and prevention programmes of the epidemic, yet HIV/AIDS has continued to notoriously spread geometrically. A major concern with this phenomenon is the rate at which the epidemic spreads among the youths, especially the adolescents' cluster in Africa. For reasons yet unexplained fully by epidemiologists and social scientists, Blacks are disproportionally at greatest risk of infections with HIV and AIDS death [2].

The prevalence of HIV among the young population in Ghana of between 15 to 24 years is at $1.1 \%$, between 45 to 49 years is highest at 5.6\%, and between 35 to 39 years at 3.5\% with 15 to 19 being the lowest at $0.6 \%$ [3]. But HIV prevalence is higher among young women (1.5\%) than among young men $(0.2 \%)$ and the epidemic is highest (4.7\%) among women between the ages of 23 to 24 years and lowest $(0.3 \%)$ among women of ages 15 to 17 years. This trend has become worrisome as Ghana recorded an alarming 70.15\% increase in HIV/AIDS cases from 12,000 new infections in 2015 to 20,148 in 2016 i.e. in just one year [4].

Knowledge of HIV/AIDS is widespread globally and has shown enormous influence on the sexual behaviour of many informed individuals. Awareness rate of HIV is generally high among 
men (96\%) than among women (93\%) [5]. Geographically, awareness is higher in urban areas (97.3\%) than in rural areas (89.2\%) but $54 \%$ of women and $70 \%$ of men are aware that condom usage can help reduce the risk of HIV infection [6].

Comparative studies conducted [5] have shown that women in Africa are more affected with HIV/AIDS than their men counterparts. A recent investigation in Canada [7] suggests that the number of women contracting HIV/AIDS is on the increase the reason for which has not been well accounted for. Many societies place the gender role of women in a position which makes it rather difficult for women to protect themselves against HIV/AIDS transmission. For examples, women have less access to education, income and employment due to cultural reasons [8] and eventually limit the women's ability to confidently negotiate for safe sex and to access HIV/AIDS prevention services.

Habinshuti [9] confirms the exclusion of individuals with disabilities, in most cases, from HIV and AIDS prevention and AIDS outreach efforts assuming that they are sexually inactive. The usual conclusion is that they have little or no risk for HIV infection. But this assumption has been proven wrong by a World Bank report and notes that individuals with disabilities have equal or greater exposure to all known risk factors for infection. There is the perception that knowledge of the mode of HIV and AIDS transmission and prevention among students with disabilities is inappropriate [9]. But knowledge of HIV/AIDS is significant for decision making with regards to sexual behaviour of the individual. One's perception and sexual behaviour habours a deeper understanding of his/her level of information about HIV/AIDS. For instance, Nzioka [10] found out that in Kenya, boys perceive sexual activity as part of their initiation into manhood, and getting a girl impregnated makes one to be respected as a real man, while contracting a sexually transmitted infection is a sign of being initiated into manhood.

Literature on HIV/AIDS knowledge across the various categories of groups and individuals has been enormous. This has aided such people to develop better perspectives and make better choices regarding their sexual behaviours and the contraction of HIV/AIDS. What has not been well researched and which remains a threat for Ghana to achieve all the sustainable development goals is the response to what perspectives and sexual behaviours the hearing impaired youth hold about HIV/AIDS and how have these factors influence their knowledge of the epidemic. How different are the sexual behaviours and HIV/AIDS knowledge of the male and female hearing impaired and to what extent do the hearing impairs sexual behaviour impact on their knowledge of HIV/AIDS remains a gray area in the Ghanaian community.

\section{METHODOLOGY}

The study was conducted among selected special schools in Ghana's ten regions: Northern, Upper East, Upper West, Brong Ahafo, Ashanti, Eastern, Western, Volta, Central and Greater Accra. Currently, there are 15 special schools and units for students with hearing impairments at the basic level.

To achieve the study objective of assessing HIV/AIDS Knowledge among the Hearing Impaired: Perceptions and Sexual Behaviours of students from Special Schools in Ghana, mixed method design was considered most suitable. This research approach allowed detail gathering of data on adolescents with hearing impaired knowledge and sexual behaviour using multiple data sources for easy triangulation.

The target population of the study was all adolescents with hearing impaired in Ghanaian special schools. At the time of this study there were 1,360 adolescents with hearing impairment, consisting of 794 [58.3\%] boys and 566 [41.6\%] girls in the selected special 
schools (Table 1). A representative sample was selected, guaranteeing the appropriateness and validity of the study [11] using a scientific sample determination formula and procedure [12]. Inappropriate sample size could lead to sampling bias.

$\mathrm{n}=\frac{N}{1+N e^{2}}$

Where:

$\mathrm{n}=$ the size of the sample

$\mathrm{N}=$ the size of the population

$\mathrm{e}=$ the margin of error

The Conference of Heads of Special Schools [13] put the total population of deaf students in the country as 1,360 . Therefore, computation for the sample size was done as:

$\begin{array}{ll}\mathrm{n} & =\frac{1360}{1+1360(0.05)^{2}} \\ \mathrm{n} & =\frac{1360}{4.4}=309.09\end{array}$

Approximately, $\mathrm{n}=310$

Also, to avoid respondents' attrition and mortality rate (failure to complete and return questionnaire), the actual sample size $\left(\mathrm{n}_{\mathrm{a}}\right)$ was calculated. This was done using this formula:

$\mathrm{n}_{\mathrm{a}} \quad=\frac{n}{e r r}$

$\mathrm{n}_{\mathrm{a}} \quad=$ actual sample size

$\mathrm{n} \quad=$ sample size

err $\quad=$ expected response rate

Therefore,

$\mathrm{n}_{\mathrm{a}} \quad=\frac{310}{0.836}=370 \cdot 8 \cdot$ i.e. 371

Based on the above calculation of the sample size, 371 sample questionnaires were sent to the field and administered to the participants. The sample frame from which sample was drawn from the population is shown in the Table 1. 
Table 1: A distribution of the sample frame in basic schools for the deaf in Ghana

\begin{tabular}{rllccc}
\hline S/N & Name of School & Region & Boys & Girls & Total \\
\hline 1 & Ashanti School for the Deaf (Jamasi) & Ashanti & 83 & 70 & 153 \\
2 & Bechem School for the Deaf. (Bechem) & Brong Ahafo & 25 & 30 & 55 \\
3 & Cape Coast School for the Deaf & Central & 70 & 43 & 113 \\
4 & Gbeogo School for the Deaf (Gbeogo) & Upper East & 61 & 42 & 103 \\
5 & Kibi School for the Deaf (Kyebi) & Eastern & 55 & 40 & 95 \\
6 & Savelugu School for the Deaf (Savelugu) & Northern & 45 & 32 & 77 \\
7 & Sekondi School for the Deaf (Nchaban) & Western & 59 & 33 & 92 \\
8 & Volta school for the Deaf (Hohoe) & Volta & 44 & 19 & 63 \\
9 & Salvation Army School for the Deaf & Central & 22 & 17 & 39 \\
10 & Koforidua School for the Deaf (Koforidua) & Eastern & 73 & 49 & 122 \\
11 & Demonstration School for the Deaf. & Eastern & 24 & 36 & 60 \\
12 & Wa School for the Deaf (Wa) & Upper West & 71 & 52 & 123 \\
13 & University Practice (Unit) (Winneba) & Central & 21 & 14 & 35 \\
14 & Agona Swedru School for the Deaf & Central & 49 & 28 & 77 \\
15 & Adjei Kojo School for the Deaf & Greater Accra & 92 & 61 & 153 \\
\hline & & & 794 & 566 & 1,360 \\
\hline
\end{tabular}

Source: [13]

In order to have less risk of bias, and to be able to manage large and widely dispersed population of students with hearing impairment in the country, multi-stage sampling technique of probability sampling method was used to select the sample from the sampling frame (Table 1). To do this, the following steps were taken into account:

a) All children with hearing disabilities in each of the fifteen (15) schools for the deaf in the country were considered (Table 1 ).

b) All schools for the deaf were grouped into regions (ten regions).

c) Four regions (Brong Ahafo, Northern, Upper East and Upper West Regions) were randomly selected.

d) Thereafter, all schools for the deaf in the four regions were considered.

e) Finally, all students with impairments in the four regions were randomly selected. According their characteristics.

In order to take care of the sample characteristics, sample proportion (\%) formula $=\frac{n}{N} \%$ was applied. Where $\mathrm{n}=$ Actual sample size and $\mathrm{N}=$ population [14].

\section{DATA ANALYSIS METHOD}

Descriptive and inferential statistics were employed in analysing the quantitative data gathered. The hypothesis was tested at 5\% confidence level applying Pearson correlation coefficient, Fisher F-test and independent t-test. For the qualitative data gathered, open code system was applied in identifying main and sub themes characterising the narrative of adolescents with hearing impairment knowledge on HIV/AIDS and sexual behaviours. Data were gathered from in-depth interviews conducted on adolescents with impairment in selected special schools in Ghana. The qualitative data gathered from the in-depth interviews were analysed using interpretive phenomenological analysis and the three coding methods (open, axial and selective coding) of grounded theory methodology.

\section{RESULTS AND DISCUSSIONS}

There is sufficient evidence relating gender to the relative access to reproductive information and as such men and women might differ in their sexual knowledge and behaviour. In this paper the question 'do the knowledge of HIV/AIDS and sexual behaviour of male adolescents with hearing impaired differ from that of their female counterpart? 
The study revealed that female students have more exposure to HIV/AIDs education than their male colleagues. Hearing impaired female students regularly receive information on HIV/AIDs in school and at home. Family members often think that their female wards are more vulnerable to sexual abuse, harassment, teenage pregnancy and HIV/AIDs than their age peers without disabilities. They explained that parents and family members often counsel them, especially, whenever they realized that they [students] are of age and are likely to have close relationship with the opposite sex. For example, a fourteen (14) year old female research participant, who had two (2) sexual partners revealed:

The first time I heard of AIDs was when my elder sister realized that I was menstruating. She was surprised because of my age. I was thirteen by then. The first thing she did was to talk to me about how to protect myself. It was during this talk she mentioned AIDs. Of course, I heard of it in school, but I did not know that the disease was that dangerous. She told me to always use condom to protect myself against pregnancy and AIDs. Since then, I don't allow my boyfriends to do it without a condom. And he understands me better. That is why I love deaf partners because if hearing people have the sickness and they will never tell you (Verbatim comment by BSDR 2).

In a similar vein, seventeen (17) year old male, who had a girlfriend without hearing impairment revealed how he got information about HIV/AIDs.

I am 17 years old. I have one girlfriend who is hearing. I got to know of HIV in hospital. I went with my mother because my little sister was sick. The doctor asked us to go for blood test. And we went to a wrong room, where many people who had the disease were waiting and watching TV. I was so scared. In the room, there were posters of people with the disease. When we came out I saw similar posters. And I took my time to read it. I was angry my mother did not tell me about the disease. But now, I and my girlfriend take our time to read about it. We know HIV/AIDS is a bad disease. So we use condom to stop us from getting AIDS. My partner will not agree to have sex with me without condom. She told me there is no medicine for HIV/AIDs and that African people who get HIV/AIDs will die (Verbatim comment by GSDR 6).

Although both male and female students disclosed having access to HIV/AIDs knowledge and information, one might consider female students having tendency of being exposed to lots of information on HIV/AIDs than their male colleagues. Most of the female participants unearthed that they get information about HIV/AIDs and other sexual related diseases from parents, siblings, other family members and neighbours. Because of their disabilities, concerned parents, siblings and neighbours often consider them vulnerable enough to be coerced into unwanted and unprotected sexual activities, which could lead to unwanted pregnancies, HIV/AIDs infection and other sexually transmitted diseases. For this reason, females with hearing impairment are often educated about unwanted teenage pregnancy, HIV/AIDs and related diseases.

\section{Hypotheses one}

\section{TESTING HYPOTHESES}

$\mathbf{H}_{\mathbf{0}}$ : There is no relationship between adolescents with hearing impairments' Knowledge of HIV/AIDs and their sexual behaviour.

$\mathbf{H}_{\mathbf{a}}$ : There is significant relationship between adolescents with hearing impairments' Knowledge of HIV/AIDs and their sexual behaviour.

To test Hypotheses one, data were collected using self-developed HIV/AIDS knowledge scale, risky sexual behaviour scales and demographic variables of adolescents with HI were used. 
Table 2, provides information on the relationship between students' knowledge of HIV/AIDS and risky sexual behaviour.

The result indicates that there was a statistical significant relationship between students' knowledge of HIV/AIDs and Sexual behaviour. Pearson $r(308)=+.85, p<.00$ (two tailed) ${ }^{2}$. The $r^{2}$ was .73; thus, indicating about $73 \%$ of the variances in risky sexual behaviour could be predicted from lack of knowledge of HIV/AIDs. The positive sign implies positive relationship, implying that students who have knowledge of HIV/AIDS tend not to take risky sexual behaviours, whereas those with limited knowledge of HIV/AIDS are most likely to engage in risky sexual practices. Based on the analysis, it is safe to reject the Alternative hypothesis $\left(\mathrm{H}_{1}\right)$ in favour of the Null hypothesis $\left(\mathrm{H}_{0}\right)$ which posited that there was a significant relationship between adolescents with hearing impairments' knowledge of HIV/AIDs and their risky sexual relationships.

Table 2: Correlation between HIV/AIDS knowledge and sexual behaviour

\begin{tabular}{llll}
\hline & & HIV AIDS Knowledge & Sexual Behaviour \\
\hline \multirow{3}{*}{ HIV AIDS Knowledge } & Pearson Correlation & 1.00 & $\mathbf{. 8 5 0}$ \\
& Sig. (2-tailed) & & $\mathbf{. 0 0 0}$ \\
& $\mathrm{N}$ & $\mathbf{3 1 0}$ \\
Sexual Behaviour & Pearson Correlation & $.850^{* *}$ & 1.00 \\
& Sig. (2-tailed) & .000 & \\
$\mathrm{~N}$ & 310 & 310
\end{tabular}

**. Correlation is significant at the 0.01 level (2-tailed).

*. Correlation is significant at the 0.05 level (2-tailed)

\section{Hypotheses two}

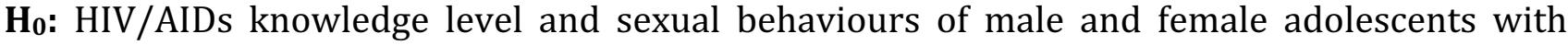
hearing impairments do not differ significantly.

$\mathbf{H}_{\mathbf{a}}:$ HIV/AIDs knowledge level and sexual behaviours of male and female adolescents with hearing impairments differ significantly.

The aim of hypotheses two was to confirm whether or not the sexual behaviours of females and males differ significantly. Confirmatory statistic (independent t-test) of the inferential statistic was employed to test the hypotheses. Test results are presented in 2 and 3.

Table 3: Group statistics for adolescents' knowledge of HIV/AIDs

\begin{tabular}{clllll}
\hline Construct & Gender & N & Mean & Std. & Std. Error \\
\hline \multirow{2}{*}{ Students' Knowledge of HIV AIDS } & Male & 176 & 46.27 & 13.045 & 0.983 \\
& Female & 134 & 29.21 & 10.177 & 0.879 \\
\hline
\end{tabular}

Source: Field data, 2015

Table 4: Independent sample t test for HIV/AIDs knowledge

\begin{tabular}{|c|c|c|c|c|c|c|c|c|c|c|}
\hline & & \multicolumn{6}{|c|}{$\begin{array}{l}\text { Levine's Test for Equality of } \\
\text { Variances }\end{array}$} & \multicolumn{3}{|c|}{$\begin{array}{c}95 \\
\% \mathrm{Ci} \\
\end{array}$} \\
\hline & & $\mathbf{F}$ & Sig & $\mathbf{T}$ & Df & $\begin{array}{l}\text { Sig } \\
2-\mathrm{t}\end{array}$ & MD & Std. & Low & Upp \\
\hline \multirow[t]{2}{*}{$\begin{array}{l}\text { Students' knowledge of } \\
\text { HIV/AIDS }\end{array}$} & $\begin{array}{l}\text { Equal variances } \\
\text { assumed }\end{array}$ & 13.26 & 0.0 & 12.51 & $\begin{array}{c}308 \\
307.8\end{array}$ & 0.00 & $\begin{array}{c}17.0 \\
6.0 \\
17.0\end{array}$ & $\begin{array}{l}1.3 \\
6.0 \\
1.3\end{array}$ & $\begin{array}{c}14.3 \\
8 \\
14.4\end{array}$ & $\begin{array}{c}19.7 \\
4.0 \\
19.6\end{array}$ \\
\hline & \multicolumn{3}{|c|}{ Equal variances not assumed } & 12.93 & 1 & 0.00 & 6.0 & 2.0 & 6 & 5.0 \\
\hline
\end{tabular}

Source: Field data, 2015 
An independent sample $t$ test output presented in Table 3 shows group statistics for students' knowledge of HIV/AIDs for gender. It is obvious that HIV/AIDs knowledge mean score for 134 female students was 29.21 with a standard deviation of 10.18 , while for 176 male students had a mean score of 46.27 with a standard deviation of 13.05. Undoubtedly, the group statistics for HIV/AIDS knowledge indicates that there is a difference between female and male students' HIV/AIDS knowledge due to the difference in the mean scores. The difference in mean HIV/AIDs Knowledge score was found to be statistically significant, $t(308.00)=12.51, p=.00$ $(p<0.05)$, two tailed. The mean HIV/AIDs Knowledge score for female $(\mathrm{M}=29.21, \mathrm{SD}=10.18)$ was lower than that of males $(M=46.27, S D=13.05)$. The $95 \% \mathrm{CI}$ for the differences between these group means, $\mathrm{M}_{1}-\mathrm{M}_{2}$, had a lower bound of 14.38 and an upper bound of 19.74. This study suggests that male students with hearing impairments' knowledge of HIV/AIDs are significantly different from that of the females. Therefore, the alternative hypothesis $\left(\mathrm{H}_{1}\right)$, which claimed that there was no statistical significant difference between male and female students' knowledge of HIV/AIDs, was rejected in favour of the Null hypothesis $\left(\mathrm{H}_{0}\right)$, which asserted that there was a significant difference between male and female students' knowledge of HIV/AIDs.

Analysis of the data generated for each of the dependent variable showed that they were normally distributed with only one outlier in each group. The outliers however were not extreme enough to require data transformation; they were retained in the analysis. Levene's test for equality of variances showed no significant difference between the variances. Examination of the analysed data revealed that HIV/AIDS knowledge among the hearing impaired was normally distributed for both groups and that there was homogeneity of variance as assessed by Levene's Test for Equality of Variances.

On the qualitative part of the study, the findings on students' sexual behavioural practices appeared to be in congruent with the quantitative results. In-depth interviews with most female and male students disclosed male students are most likely to engage in risky sexual behaviours than their female partners. For instance, a good number of male research participants said that they preferred having raw sex with their girlfriends to using condoms during sex. An interaction with a seventeen (17) year old male student on the use of condom during sex brought startling revelations. The male student said: "I know AIDs is real. But I don't like using condom during sex because I derive more pleasure in having sex without a condom than when I use it. Every boy wants to get every drop of satisfaction from the girl friend". Most boys disclosed that they felt more comfortable asking for sex without a condom from their girlfriends than their girlfriends. For instance, a fifteen-year-old male student with a multiple sexual partners said: "Asking her to do it without a condom and many other things won't make me lose my respect, but she cannot ask for sex and she will feel shy to say don't use condom".

Most of the male students agreed that there was something "very hot" in being able to have sex without a condom. Although one male student said it was dangerous not to protect "himself", he did admit that he preferred "going raw". But generally, both female and male students admitted to being more open about what they wanted during sex and more physically satisfied when they did not use condom and other contraceptives. During one of the interview sessions, a 24-year-old female student complained:

Boys like the fastest way to having sex, their fantasy and the willingness to try new things is what matters to most boys when sex is concerned. They don't care about what happens now. It is their fantasies and sexual adventures that keep them moving. They prefer to sleep with the hottest girl in school or in town. They don't care if the girls have diseases or not. What they care for is sex. When you insist that they should protect themselves, they leave you and go for other girls. They may regret later. But it 
is always too late. When I was 15, I had 3 boyfriends. All of them were good, so we did not use condom. They used to wash their penis with water after sex. They use to say that condom is not good and sweet and it cannot stop AIDS.

However, almost all research participants agreed that sex without a condom was the quickest way to getting a satisfying sex when they felt the urge. They disclosed that boys with hearing impairment preferred sexual experiences with no drama and no obligations whatsoever. They preferred to have sex without preconditions or a reminder of all those diseases, contraceptives, unwanted pregnancy. "What they need is sex and they want to have it instantly", a 19-year-old female student said.

\section{Hypothesis three}

$\mathbf{H}_{\mathbf{0}}$ : There is no sexual behaviour difference between male and female adolescents with hearing impairments.

$\mathbf{H}_{\mathbf{a}}$ : there is no difference between male and female adolescents with hearing impairments sexual behaviour.

The aim of these hypotheses three was to confirm whether or not the sexual behaviours of females differ significantly. Test results of sexual behaviours of female and male adolescent with HI are presented in Table 4 and Table 5 respectively.

Table 5: Group statistics for adolescent sexual behaviour

\begin{tabular}{llcccc}
\hline Construct & Gender & N & Mean & Std. & Std Error \\
\hline \multirow{2}{*}{ Students' Sexual Behaviour } & Male & 176 & 39.15 & 11.11 & 0.84 \\
& Female & 134 & 26.37 & 9.45 & 0.82 \\
\hline
\end{tabular}

Source: Field data, 2015

An independent $t$ test was performed to assess if there was a difference between the two independent groupings (female and male risky sexual behaviours. Table 3 indicates that data were normally distributed in the gender grouping. Leven test for equality of variances was performed. Result indicated that $F=5.10, P=.02(p<0.05)$, suggesting that there was no significant violation of equal variance assumption, therefore Equal variances can be assumed, and test the hypothesis using the $t$ test row of the results. The mean risky sexual behaviour differed significantly, $t(308.00)=10.69, p=.00(p<0.05)$, two tailed. Mean risky sexual behaviour for male group $(M=39.15, S D=11.11)$ was higher than that of their female counterparts was $(M=26.37, S D=9.45)$. The $95 \% \mathrm{CI}$ for the differences between the male and female group means, $\mathrm{M}_{1}-\mathrm{M}_{2}$, had a lower bound of 10.42 and an upper bound of 15.13. Therefore, we can reject the Alternative $\left(\mathrm{H}_{1}\right)$ in favour of the Null hypothesis $\left(\mathrm{H}_{0}\right)$ and conclude that a statistically significant difference exits between male and females' risky sexual behaviours.

Table 6: Independent sample t test for adolescent sexual behaviour

\begin{tabular}{|c|c|c|c|c|c|c|c|c|c|c|}
\hline & & \multicolumn{4}{|c|}{$\begin{array}{c}\text { Levine's Test for Equality of } \\
\text { Variances }\end{array}$} & \multicolumn{5}{|c|}{$\begin{array}{c}95 \\
\% \mathrm{Ci}\end{array}$} \\
\hline & & $\mathbf{F}$ & Sig & $\mathbf{T}$ & Df & $\begin{array}{l}\text { Sig } \\
2-t\end{array}$ & MD & Std & Low & Upp \\
\hline \multirow[t]{2}{*}{$\begin{array}{l}\text { Students' knowledge } \\
\text { of HIV/AIDS }\end{array}$} & $\begin{array}{l}\text { Equal variances } \\
\text { assumed }\end{array}$ & 5.895 & $\begin{array}{l}0.0 \\
2\end{array}$ & 10.69 & $\begin{array}{l}308.0 \\
304.1\end{array}$ & 0.00 & $\begin{array}{l}12.78 \\
.00\end{array}$ & $\begin{array}{l}1.2 \\
0.0 \\
1.1\end{array}$ & $\begin{array}{l}10.4 \\
2 \\
10.4\end{array}$ & $\begin{array}{l}15.13 \\
.00 \\
15.08\end{array}$ \\
\hline & Equal variances & t assum & & 10.92 & & 0.00 & 12.78 & 7.0 & 7 & .00 \\
\hline
\end{tabular}

Source: Field data, 2015 
Previous research [15] examined gender differences in the belief that adolescents are not at risk of HIV/AIDS infection. The investigation comprised 366 male and female participants selected from Kenya, South Africa and Tanzania. There were statistically significant gender differences in the belief that adolescents were not susceptible to HIV/AIDS transmission. In Tanzania, men had a knowledge score of 76.7 per cent compared to a sore of 73.2 per cent for women. Kenya male participants scored 79.8 per cent, whereas women had a score of 80.6 per cent. For South Africa, men scored 77.4 per cent compared to 73.4 per cent for women. In all the three countries, the gender differences were statistically significant; with males in South Africa and Tanzania outperforming females, whereas in Kenya the female respondents outperformed male respondents.

Aluede et al [16] assessed university students level of knowledge about HIV/AIDS with a sample comprising 900 undergraduate students consisting of 520 male and 380 female students. The results showed that the respondents had a highly favourable knowledge regarding HIV/AIDS. Furthermore, the results showed a statistically significant gender differences in HIV/AIDS knowledge with male students showing higher knowledge of HIV/AIDs than was the case with female participants.

Mhloys et al [17] investigated gender differences in HIV/AIDS knowledge among 933 university students in Zimbabwe on the basis of cultural, sociological and economic variables. Male participants expressed the views that: they had the right to dominate women, and that they were the ones to decide the use of condom. In contrast, the women participants acknowledged the gender cultural attitude towards women and went further by asserting their support for women's rights to sexual activity.

Ugbona et al [18] examined gender differences in students' knowledge of HIV/AIDS on a sample of 1748 secondary school students aged 12-19 years of age drawn from 12 schools. Their knowledge was high as it stood at $80 \%$. However, there was no gender difference in their knowledge of HIV/AIDS. Montosh et al [19] carried out a study of 2399 university students in Lagos, Nigeria, in which participants had a moderate knowledge of HIV/AIDS.

It was also reported that female participants were predisposed to contracting HIV/AIDS, because of their engagement in high risk sexual behaviour for financial reasons. In terms of gender difference in HIV/AIDS, no difference of significance was observed. According to a cross-national survey carried out in Ethiopia, Mali and Nigeria 97-98\% of men had knowledge of HIV/AIDS compared to $86-90 \%$ for women who were just as knowledgeable. Similar survey carried out in Kenya and Madagascar showed gender difference showing that men showed more than women. The study carried out in Rwanda, however, showed no gender difference in HIV difference in HIV/AIDS between females and males.

Disability further worsens women access to education, reproductive health, knowledge of HIV/AIDS and preventive measure [20,21]. Women with disabilities often experience double discrimination due to the intersection of gender and disability [22]. For Ghanaian women with disabilities, the situation is more complicated, given the intersection of disability, gender, poverty, cultural beliefs and practices, negative perceptions about their capabilities, and geographic area $[23,24,25,26,27,28,29]$.

\section{CONCLUSION AND RECOMMENDATION}

The study revealed that the female students seemed to have more exposure to HIV/AIDs education than their male colleagues. Consequently female adolescents with hearing impairment were found to have more knowledge of HIV/AIDS than their female counterparts. 
Because female students surveyed were found more likely to be exposed to sex education by their parents and/or school authority as they are presumed more vulnerable than their male counterparts to HIV/AIDS risky sexual behaviour.

Similarly male adolescents with hearing impairment HIV/AIDS risky sexual behaviour was found to differ significantly from that of their female counterparts. HIV/AIDS sexual risky behaviour of male was found to be higher than that of their female counterparts. Thus male adolescents with hearing impairment stand higher risk of contracting HIV/AIDS compare with their female counterparts.

The general view that female students may have less information and knowledge on HIV/AIDS compare with their male counterpart has to be relooked. And that parents and school authorities should target both male and female students in their HIV/AIDS education. It is further recommended that sex educational programmes aid at correcting risky sexual behaviour and preventing HIV/AIDS and other sexual transmitted disease spread should target male adolescent as well as girls. Also parents and school authorities should be more opened in their sex education to both male and female adolescents with disability.

\section{References}

Adeniyi SO, Olufemi-Adeniyi OA (2015). HIV/AIDS among Adolescents with Hearing Impairment in Nigeria: Issues, Challenges and Strategies for Prevention in Achieving Millennium Development Goals. An Int ernational Multidisciplinary Journal. 8 (2): 38-51.

CDC (2018). HIV and African Americans: HIV Diagnoses in 2016. www.cdc.gov/hiv [retrieved 14/11/2018].

Ghana Aids Commission (2016). Annual report on HIV/AIDS.

www.myjoyonline.com

Burgoya AD, Drummond P (2008). Knowledge of HIV and AIDS in women in Sub-Saharan Africa. African Journal of Reproductive Health. 12(2): 14-31.

LEA (2015). Legal Environment Assessment for HIV/AIDS response in Nigeria.

Gahagan J (2012). Gender matters in HIV prevention. Online at:www.catie.ca/en/pf/spring-2012/gender mattersHIV-prevention

Antonio A, Tuffley D (2014). The Gender Digital Divide in Developing Countries. Future Internet. 6: 673-687.

Habinshuti G (2015). Influence Of Disability On Access To Hiv And Aids Information By Students With Disabilities In Institutions Of Higher Education In Rwanda. A Research Thesis Submitted For The Degree Of Doctor Of Philosophy (Special Needs Education) In The School Of Education Of Kenyatta University.

Nzioka C (2001). Perspectives of adolescent boys on the risks of unwanted pregnancy and sexually transmitted infections: Kenya. Reprod Health Matters. 9(17):108-17.

Bartlett JE, Kotrlik JW, Higgins CC (2001). Organizational Research: Determining Appropriate Sample Size in Survey Research. Information Technology, Learning, and Performance Journal. 19: 43-50.

Cooper DR, Schindler PS (2001). Business Research Methods. McGraw-Hill Higher Education, London.

COHASS (2015). Annual report; Conference of Heads of Assisted Second cycle Schools.

Mwamwenda TS (2014). African university adolescents' gender differences in HIV/AIDS vulnerability. Journal of AIDS and HIV Research, 6(2): 39-43.

Alulede O, Imhonde H, Maliki A Alutu A (2005). Assessing Nigerian university students' knowledge about HIV/AIDS. Journal of Social Sciences, 11(3), 207-213.

Ugbona, H. A., Kooffel, M. E. and Nwauche,A. A. (2011). Gender differences in students' knowledge of HIV/AIDS in the Niger Delta, Nigeria. Journal of Clinical Medicine and Research, 31(1), 20-22.

Montoh SO, Asagwara CG, Meriamu UH (2011). Male gender roles and sexuality: Implication for university girls HIV/AIDS awareness in a Nigerian university. Journal of International Women's Studies, 8(4), 148-152. 
Groce N, Kett M (2013). Leonard Cheshire Disability and Inclusive Development Centre; The Disability and Development Gap; Working Paper Series: No. 21

Groce N, Kett M (2014). Leonard Cheshire Disability and Inclusive Development Centre; Youth with Disabilities; Working Paper Series: No. 23

Groce N, Kett M, Lang R, Trani JF (2011). "Disability and poverty: the need for a more nuanced understanding of implications for development policy and practice" Brown School Faculty Publications. Paper 48.

Ortoleva S Lewis H (2012). Forgotton Sisters - A Report on Violence Against Women With Disabilities: An Overview of its Nature, Scope, Causes and Consequences. Northeastern University School of Law Research Paper no. 104-2012. Available at SSRN: http://papers.ssrn.com/sol3/papers.cfm.

Terry PE, Mhloys M, Masavaure T Adlis S (2005). Gender equity and HIV/AIDS prevention: Comparing gender differences in sexual practices and beliefs among Zimbabwe university students. International Quarterly of Community Helth Education, 24(1), 29-43. 